1 Climatic events inducing die-off in Mediterranean

2 shrublands: Are species responses related to their

\title{
functional traits?
}

4

5 Francisco Lloret $^{1^{*}}$, Enrique G. de la Riva ${ }^{2}$, Ignacio M. Pérez-Ramos ${ }^{3}$, Teodoro

6 Marañón ${ }^{3}$, Sandra Saura-Mas ${ }^{1}$, Ricardo Díaz-Delgado ${ }^{4}$, Rafael Villar ${ }^{2}$.

7

$8{ }^{1}$ CREAF i Unitat d'Ecologia, Dept. Biologia Animal, Biologia Vegetal i Ecologia,

9 Universitat Autònoma Barcelona, Edifici C, Campus UAB, 08193, Cerdanyola

10 del Vallès, Barcelona, Spain

112 Área de Ecología, Facultad de Ciencias, Universidad de Córdoba. 14071

12 Córdoba, Spain

$13{ }^{3}$ IRNAS, CSIC, Av. Reina Mercedes, 10. 41012 Sevilla, Spain

$14{ }^{4}$ EBD, CSIC. c/ Americo Vespucio, s/n, Isla de la Cartuja. 41092 Sevilla, Spain 15

16 * corresponding author (francisco.lloret@uab.cat) 


\section{Abstract}

19 Extreme climatic episodes, likely those associated to climate change, often

20 result in profound alterations of ecosystems and, particularly, in drastic events

21 of vegetation die-off. Species attributes are expected to explain different

22 biological responses to these environmental alterations. Here we explored how

23 changes in plant cover and recruitment in response to an extreme climatic

24 episode of drought and low temperatures were related with a set of functional

25 traits (of leaves, roots and seeds) in Mediterranean shrubland species of SW

26 Spain. Remaining aerial green cover (RAGC) two years after the climatic event

27 was positively related with specific leaf area (SLA) and leaf proline content, and

28 negatively with leaf water potential and $\delta^{13} \mathrm{C}$. Plant cover resilience $-\mathrm{i}$. e. the

29 ability to attain pre-event values - was positively related to a syndrome of traits

30 characterized by a higher efficiency in water use and uptake. Higher SLA and

31 lower WUE characterized other species that were able to maintain green

32 biomass for a longer time period but they were less resilient at a medium term.

33 Seedling emergence was negatively associated with such syndrome, with

34 small-sized species being able to produce a large number of seedlings per

35 adult. Overall, recruitment was positively correlated with species die-off. This

36 study demonstrates the relationship between plant traits and strong

37 environmental pulses related to climatic change, providing a functional

38 interpretation of the recently reported episodes of climate-induced vegetation

39 die-off. Our findings also reveal the importance of selecting meaningful traits to 40 interpret post-event resilience processes, particularly when combined with 41 demographic attributes. 
43 Keywords: climate change, drought, extreme climate episode, plant functional 44 traits, recruitment, resilience, seed mass, specific leaf area, root traits, wateruse strategies.

\section{Introduction}

48 Plant functional traits reflect the outcome of the interactions between plant 49 species and environment as a result of selection processes (Westoby et al. 50 2002; Reich et al. 2003). Accordingly, trait composition in coexisting species

51 would be the consequence of the biogeographical and ecological contexts (Díaz 52 and Cabido 1998; Ackerly 2004). Particularly, species responses to climate 53 change are expected to obey at some extent to the traits that they exhibit (e.g. 54 Esther et al., 2010; Lloret et al. 2103). Some attempts have been made at the 55 regional scale to relate functional traits either with species demographic rates 56 (Martínez-Vilalta et al. 2011) or with expected changes of the species' climatic 57 suitability (Thuillier et al. 2006; Lloret et al. 2013). But there is still scarce 58 information on the role of plant functional traits as drivers of population-level 59 responses to climatic extreme events. There are evidences that climate change is involving an increase of 61 climatic variability (IPCC, 2013), although some uncertainties remain at small 62 spatial scales (Shih-Chieh and Auroop, 2011). This climatic variability implies a 63 higher frequency and intensity of extreme climate episodes - including heat 64 waves, cold snaps, droughts and floods - which can produce fast 65 transformations in the structure, composition and functioning of ecosystems 66 (Easterling et al. 2000). However, more detailed information on the relationships 67 between biotic processes and these climatic disturbances is needed to better 
68 understand the impact of future climatic changes on vegetation dynamics

69 (Reyer et al. 2013). Specifically, drought events have been identified as responsible in some measure for some recently reported episodes of vegetation die-off worldwide (Allen et al., 2010; Martínez-Vilalta et al. 2012). Then, changes in the functional characteristics of plant communities are likely to occur, given the remarkable differences in species sensitivity to these climatedriven disturbances (Lloret et al. 2012). Nevertheless, the different responses of coexisting species to these climate extreme events and their relationships with key functional traits remain poorly known (Koepke et al. 2010). These traitbased studies might be particularly relevant for a better understanding of the role of plant traits on community dynamics in a context of transformations of ecosystems due to climate change (Chapin 2003; Suding et al. 2008).

The demographic responses to climatic extreme episodes are expected to reflect the functional significance of traits in correspondence with such environmental stresses. Particularly, conditions derived from extreme drought conditions could be faced with mechanisms optimizing water acquisition, for instance those involving more efficient root systems. In spite of its relevance to understand plant strategies of resource use, root traits have been rarely analysed within communities (but see Pérez-Ramos et al. 2012; Prieto et al. 2015), particularly in the context of natural pulses of water scarcity (McCormak 2012; Saura-Mas and Lloret 2013). Analogously, traits associated to the control of water loss, such as water use efficiency (estimated indirectly by carbon isotopic discrimination) or evaporative surface reduction might be more likely present in those species better adapted to these drought conditions. Also, it has been proposed that species prone to establish in stressful, dry environments 
93 will probably develop a more conservative resource-use strategy characterized

94 by low values of specific leaf area (SLA), high-density tissues, low leaf-N 95 concentration and long leaf-life span (Reich et al. 1998; Díaz et al. 2004; Villar et al. 2006). Finally, regenerative traits related to plant establishment, such as 97 seed mass (Westoby et al. 2001), may help to understand population recovery 98 after climatic extreme episodes. Then, species resilience, which measures the 99 capacity of populations to recover their pre-event state, can estimate the delayed response to extreme drought events (Lloret et al. 2011). In this study we use a demographic, trait-based approach to explore how 102 coexisting woody plant species respond to a climatic extreme event, and to 103 evaluate whether these species-specific responses are related to particular 104 plant functional traits. The study system is a Mediterranean shrubland located in 105 South Spain that suffered a strong die-off as a consequence of an anomalous 106 period of low precipitation and severe cold winter (Díaz-Delgado 2006). We 107 monitored remaining green aboveground cover, adult survival and new 108 recruitment of the main species of the community, two and eight years after the 109 climatic episode. We measured traits related to light and carbon acquisition 110 (plant height, SLA, leaf chlorophyll), water acquisition and use (leaf and root dry 111 matter content, tissue mass root density, leaf water potential, carbon isotopic 112 discrimination), nutrient acquisition and use (nitrogen leaf concentration) and 113 recruitment (seed mass). Specifically, we addressed the following questions: Do 114 plant functional traits of coexisting species explain: (i) differences among 115 species die-off resulting from the climatic extreme episode? (ii) the different 116 species resilience, in terms of plant cover, eight years after the climatic 
117 episode? and (iii) differences in recruitment of seedlings and juveniles among

118 species after the climatic episode?

\section{Methods}

\section{Study site and die-off episode}

123 The study was carried on in the Doñana National Park (south-western Spain, $\left.12438^{\circ} 13^{\prime} \mathrm{N}, 48^{\circ} 10^{\prime} \mathrm{W}\right)$, at approximately $3 \mathrm{~km}$ far from the Atlantic Ocean, over a 125 large Quaternary eolic dune field that became stabilized during the Holocene. 126 The vegetation is a mosaic of wetlands, annual grasslands, shrublands and 127 woodlands dominated by Juniperus phoenicea L. subsp. turbinata (Guss.) 128 Nyman (Juniperus phoenicea hereafter) and Pinus pinea L. The study was 129 performed in shrublands (locally named 'monte blanco'), which are considered 130 to be a serial stage of J. phoenicea woodlands (García Murillo and Sousa 131 Martín, 1999). The studied sites of 'monte blanco' shrublands are dominated by 132 medium-sized (1-3 m high) shrubs such as Halimium halimifolium (L.) Willk and

133 Rosmarinus officinalis L.. Other common shrubs are the tall (2-4 m high) shrub

134 Erica scoparia L., the medium-sized shrubs Halimium commutatum Pau, Cistus 135 libanotis L., Staurancanthus genistoides (Brot.) Samp. and Ulex australis 136 Clemente, and the small-sized shrubs (0.5-1 m high) Lavandula stoechas L., 137 Thymus mastichina L., and Helichrysum pichardii Boiss. \& Reuter.

138 The climate is sub-humid Mediterranean with oceanic influence. Mean 139 annual rainfall is $560 \mathrm{~mm}$, with considerable between-year variability, ranging 140 from less than $300 \mathrm{~mm}$ to almost $1000 \mathrm{~mm}$. Mean annual temperature is 16.5 $141{ }^{\circ} \mathrm{C}$, with mean monthly values ranging from $10.0^{\circ} \mathrm{C}$ in January to $24.7^{\circ} \mathrm{C}$ in 
142 July. An episode of extreme drought occurred in the hydrological year 2004-

1432005 (October 2004 to September 2005), when total rainfall was only $173 \mathrm{~mm}$,

144 being the second driest recorded year since 1859 . Winter rainfall was $58.9 \mathrm{~mm}$,

145 less than one third of the historical average, while mean minimum temperatures

146 in January and February 2005 were respectively $1.1^{\circ} \mathrm{C}$ and $0.9^{\circ} \mathrm{C}$, substantially

147 lower than the average values $\left(5.0^{\circ} \mathrm{C}\right.$ for January and $6.1^{\circ} \mathrm{C}$ for February). This

148 episode resulted in a general die-off of the shrubland populations (Díaz-

149 Delgado 2006, Appendix 1, 2, Electronic Supplemental Material). Annual rainfall

150 recovered in the years following the episode, ranging from $468.3 \mathrm{~mm}$ in the

$1512005-2006$ hydrological year to $784.2 \mathrm{~mm}$ in 2009-2010 (Fig. 1).

152

153 Estimations of resilience and remaining green aerial biomass

154 Eighteen 25- $\mathrm{m}^{2}(5 \times 5 \mathrm{~m})$ plots were established in November 2007, 2 years 155 after the drought episode, covering the range of die-off, from $14 \%$ to $88 \%$ of 156 green plant cover. NDVI from Landsat imagery $\left(30 \times 30 \mathrm{~m}^{2}\right.$ pixels, $\left.\mathrm{n}=21\right)$

157 obtained for the site of the sampled plots did not show significant differences on

158 NDVI between November 2007 (sampling data) and 2005 (data of the end of 159 the climatic episode). These images showed a significant NDVI diminution in 1602005 when comparing to previous years, as well as canopy recovery after 2007

161 (see Appendix 3, Electronic Supplemental Material). These data support the 162 adequacy of sampling in November 2007 to assess the effect of the climatic 163 event.

164 The plots were distributed across an area of approximately $10 \mathrm{~km}^{2}$, 165 separated by at least $50 \mathrm{~m}$ from each other. In November 2007 and July 2013 166 we carried out two plant surveys recording the number of adults (including alive 
167 and dead plants), juveniles (plants established at least one year ago, but

168 without achieving the reproductive stage) and seedlings (less than one year old)

169 of all woody species present in each of the 18 plots. Species plant cover

170 (expressed as percentage) was estimated from contacts with branches

171 (excluding leaves and recent shoots) at $0.5 \mathrm{~m}$ intervals along ten $5 \mathrm{~m}$ long

172 transects, regularly distributed within the plot. Contacts were divided in two

173 categories corresponding to living (branches supporting leaves or green shoots)

174 or dead canopy (branches corresponding to recently defoliated organs,

175 recognized because they bore remaining thin tips of branches and there were

176 un-decomposed leaves on the ground beneath the contact). Dry organs with

177 signs of old decay (stumps, decomposed stems, branches without thin tips)

178 were excluded. By this sampling we could calculate an estimator of plant cover

179 suitable to compare canopy state before and after the climatic episode. Thus,

180 canopy prior to the episode was considered as the sum of living and dry plant

181 canopy in 2007. The increase of green canopy by growth of new shoots and

182 leaves between 2005 and 2007 should be considered as irrelevant with our

183 sampling, which focused on branches. Also, NDVI measures did not support a

184 strong canopy recover between these dates.

185 We calculated the remaining aerial green cover (RAGC hereafter) as the

186 percentage of living canopy in transect contacts in the 2007 survey respective

187 to the total of contacts of each species, including both living and dead canopy.

188 Although our sampling in 2007 was not simultaneous to the climate extreme

189 event, we consider that our estimation is a representative measurement of the

190 impact of the climatic episode on vegetation cover. In fact, given that delayed

191 canopy decay is common after drought episodes and disturbances, our survey 
192 allowed integrate this phenomenon without overestimating regrowth, as

193 explained above. Average RAGC values for each species were obtained 194 combining the data of the eighteen plots. We used this calculation instead of the

195 mean value of plant contacts in the eighteen plots to minimize the stochasticity 196 associated to the low abundance of certain species in some plots.

197 Species resilience to the die-off episode was estimated in 2013 from 198 plant contacts measurements. We used the relative resilience index (RR 199 hereafter) (Lloret et al. 2011), which estimates plant recovery to the state 200 previous of a given disturbance, weighting by the impact of such disturbance:

202 Relative Resilience $=($ Post-Dist $) /$ Pre

203

204 where Pre, Dist and Post indicate performance previous (Pre), immediately 205 following disturbance (Dist) and after disturbance (Post). In our case the 206 disturbance was the climate-induced die-off episode, and the respective values 207 corresponded to species plant cover (contacts) prior to the climatic episode 208 (Pre), just after the episode (2007, Dist) and eight years later (2013, Post).

210 Measurements of Plant Functional Traits

211 In late spring 2013, during the maximum peak of plant growth, healthy adults of 212 the most abundant species were randomly selected (outside the plots to avoid 213 disruptions) for measuring ten above-ground and four below-ground functional 214 traits related with morphology, physiology, reproduction and plant chemical 215 composition (Table 1). All trait measurements were carried out according with 216 the criteria defined by Pérez-Harguindeguy et al. (2013). 
Plant height (Phg) measurements were made on ten individuals using a

218 metric tape. Leaf traits, in particular specific leaf area (SLA; leaf area per unit of

219 dry leaf mass), leaf dry matter content (LDMC; dry mass per unit of water-

220 saturated fresh mass), leaf thickness (Lthick), leaf nitrogen concentration (LN)

221 and leaf chlorophyll (LChl; concentration of chlorophyll per unit of leaf fresh

222 mass) were measured in six individuals per species (see details about leaf traits

223 measures in Appendix 4, Electronic Supplemental Material). Carbon isotopic

224 ratio ( $\delta 13 \mathrm{C} ; \%$, precision of ca. $0.2 \%$ ), which is related with plant water use

225 efficiency (Farquhar et al. 1982), was obtained from a mixture of leaves

226 collected from six different individuals.

227 In addition we used two physiological traits, leaf water potential $(\Psi)$ and

228 leaf proline content (Prol), which are considered as an estimation of drought

229 stress in plants, from the values measured by Zunzunegui et al. (2005) for most

230 species (except $H$. picardii and T. mastichina) in the same study area.

231 Roots were sampled at the individual level by excavating the first 20-30

$232 \mathrm{~cm}$ of the soil layer nearby the plant basal stem for four individuals per species.

233 We selected this specific soil depth based on other studies in Doñana National

234 Park (Martínez et al. 1998) that demonstrated that the largest fraction (70\%) of

235 fine roots appears in the first $25 \mathrm{~cm}$ of soil depth. These root samples were

236 used to measure below-ground traits of fine roots $(<2 \mathrm{~mm}$ in diameter) related

237 with water and nutrient uptake (McCormak 2012): specific root area (SRA, root

238 area per unit of dry root mass), root dry matter content (RDMC, root dry mass

239 per unit of root fresh mass), root diameter (Rdiam, mean diameter), and tissue

240 mass root density (TMDr, root mass per unit of root volume). These data were 
241 obtained by analyzing the scanned root samples with WinRHIZO 2009 (Regent

242 Instruments Inc., Quebec, Canada) and further weighing the dry root mass.

243 Data of seed mass (Smass) was provided by the Seed Bank in the

244 Córdoba Botanical Garden.

245

246 Statistical analyses

247 We performed linear and quadratic polynomial fits of RAGC and RR in relation

248 with the 14 plant functional traits of the eleven dominant species of the 'monte

249 blanco' shrubland $(H$. halimifolium, H. commutatum, C. libanotis, S. genistoides,

250 U. australis, R. officinalis, L. stoechas, T. mastichina, E scoparia, H. pichardii

251 and J. phoenicea). We applied logarithmic (for SLA, Lthick, Prol, Phg and

252 Smass) or reciprocal transformation (for $L N$ ) when needed to attain normality 253 criteria.

254 Plant functional trait syndromes (patterns of the whole set of traits) 255 across species were assessed by a PCA considering the average values of 256 traits for the different species. Leaf water potential $(\Psi)$ and Leaf proline content 257 (Prol) were not included in this analysis since the information was not available 258 for some species. Then, we also performed linear fits of species RAGC and RR 259 with the respective coordinates of the first PCA component.

260 We analysed the relationships between recruitment after the die-off 261 episode and functional traits by GLMs, in which the main factor was the total 262 number of seedlings recorded in 2007 or the total number of juveniles recorded 263 in 2013 per species. In the 2013 survey, the number of seedlings was scarce 264 due to seed bank depletion (del Cacho and Lloret 2012), and was not included 265 in these analyses. We performed a GLM separately for each selected trait and 
266 for coordinates of the first PCA component describing trait syndromes as the 267 main explicative variable, and in each model we included species adult 268 abundance prior to the die-off episode (considering the sum of species 269 transects contacts from all plots) and species defoliation (estimated as the 270 difference of living and dry plant organs in transects contacts from all plots) as 271 covariates. We included these two covariates to control for the abundance of 272 species on the number of recruits and to assess the effect of the loss of canopy 273 cover on recruitment, respectively. We applied log-transformations to the

274 number of seedlings and juveniles, as well as to adult abundance (previous to 275 the die-off). We performed a step-wise selection procedure using the Akaike 276 information criterion (AIC) to select the best-fitted models. All the analyses were performed using JMP 10.0 (SAS Institute Inc.).

\section{Results}

280 The climatic extreme event reduced more that $50 \%$ of aerial green cover in 281 three of the most common species (R. officinalis, C. libanotis, H. commutatum) 282 by 2007 (Fig. 2). Canopy of the most abundant species (H. halimifolius) was 283 reduced around $25 \%$, while loss of green canopy in other large shrubs ( $U$. 284 australis, S. genistorides, E. scoparia and J. phoenicea) ranged between 10 285 and $40 \%$. Smaller shrubs, such as L. stoechas, T. mastichina and H. picardii 286 tended to be less affected, with canopy loss below $20 \%$. In 2013 , most species 287 still remained with reduced canopies compared to their state before the event, 288 ranging this value around $40-60 \%$ in $H$. halimifolium, $\mathrm{H}$. commutatum, $R$. 289 officinalis, L. stoechas, U. australis, H. picardii and E. scoparia. 
The first and second axes of the PCA ordination describing trait 291 syndromes in the studied species accounted for the 45.4 and $22.0 \%$ of the 292 variability, respectively. The first axis was positively related to Lthick, $\delta^{13} \mathrm{C}$, 293 Rdiam, Smass and negatively related to SLA, SRA, and TMDr (Fig. 3). Remaining aerial green cover (RAGC) was linearly and positively related with SLA $\left(r^{2}=0.47, P=0.02\right)$ and leaf proline content $\left(r^{2}=0.56, P=0.02\right)$, but negatively with leaf water potential $\left(r^{2}=0.46, P=0.04\right)$ and $\delta^{13} \mathrm{C}\left(r^{2}=0.38, P=\right.$ 297 0.04) (Fig. 4). RGAC showed a significant linear negative relationship with RDMC, after excluding $R$. officinalis $\left(r^{2}=0.58, P=0.01\right)$ (Fig. 4).

Relative resilience (RR) was linearly, positively related with $\delta^{13} \mathrm{C}\left(r^{2}=\right.$ 300 0.43, $P=0.03)$, Smass $\left(r^{2}=0.53, P=0.01\right)$, Rdiam $\left(r^{2}=0.39, P=0.04\right)$ and the 301 first PCA axis $\left(r^{2}=0.44, P=0.03\right)$, while it was negatively with $\operatorname{TMDr}\left(r^{2}=0.38\right.$, 302 $P=0.04)$ (Fig. 5). Quadratic polynomial fits did not improve linear ones in the RAGC and RR analyses.

The number of seedlings in 2007 for each species was positively related with SLA and LN and negatively with LDMC, Lthick, $\delta^{13} \mathrm{C}$, Smass and the score 306 in the first PCA axis (Table 2). The number of seedlings was also positively 307 related to the species defoliation, except for the model analysing LN (Table 2). Adult abundance prior die-off was not significantly related with the number of seedlings and, therefore, it was removed from the models.

The number of juveniles in 2013 was negatively related to the first PCA 311 axis $\left(r^{2}=0.91, F=28.32, P=0.003\right.$, estimate $\left.=-0.702\right)$. But we failed to find 312 significant relationships when analysing the functional traits separately, except 313 for LDMC, which also exhibited a negative relationship $\left(r^{2}=0.77, F=11.4, P=\right.$ 3140.01 , estimate $=-20.8$ ). The number of juveniles was again positively related 
315 with species defoliation $(\mathrm{F}=17.0, P=0.009$, estimate $=2.12$ and $\mathrm{F}=9.43, P=$ 3160.022 , estimate $=0.408$, for the first PCA axis and the LDMC models, 317 respectively), while adult abundance prior die-off was not.

\section{Discussion}

320 Plant functional traits as drivers of response to the extreme climatic episode

321 Results from this study demonstrated that some key functional traits of plant 322 species are able to explain a relevant part of the between-species variability in 323 the response to climatic extreme events. Plant functional groups based on 324 certain key traits have been largely used to describe community patterns along 325 ecological and biogeographical gradients (e.g. Diaz and Cabido 1998; Thuillier 326 et al. 2006; Esther et al. 2010). Previous studies have analysed how key 327 functional traits strongly change across local environmental gradients (e.g. 328 Ackerley 2004; Pérez-Ramos et al. 2012; de la Riva et al. 2015; all of them 329 under Mediterranean conditions). Our results expand these approaches by 330 demonstrating that several key traits may also explain species responses to 331 sporadic pulses of strong environmental stress - in our case, extreme conditions of drought and cold -, and might be thus act as drivers of a succeeding resilience.

The observed loss of green canopy was consistent with damage caused 335 by the drought in the 2004-2005 hydrological year, but also with the extreme 336 cold occurring in the 2005 winter. Low temperature is a limiting factor in 337 Mediterranean Basin ecosystems (Mitrakos 1980; Larcher 1981), as evidenced 338 by field physiological measurements (Karavatas and Manetas 1999; Granda et 339 al. 2014) and experiments under controlled conditions (Logullo and Salleo 
340 1993; Oliveira and Peñuelas 2004; Cavender-Bares et al. 2005). Symptoms of 341 cold-induced impact include foliage damage (Oliveira and Peñuelas 2004), and 342 the involved physiological mechanisms comprise xylem cavitation, loss of leaf 343 stomatal conductance to water vapour and decline of photochemical efficiency 344 of photosystem II (Granda et al. 2014). In fact, we are not able to disentangle 345 the effects of the two climatic stressors (extreme drought and cold), indeed a 346 synergistic effect between them is likely to have occurred (see other examples 347 in Willson and Jackson 2006; Granda et al 2014).

349 The role of water-use traits.- In general, the studied woody plant species 350 showed a predominant conservative resource-use strategy (Reich et al. 1998; 351 Díaz et al. 2004; Villar et al. 2006), likely due to the homogeneous stressful 352 Mediterranean environment (with a strong seasonal water deficit) where they 353 inhabit. Within this functional context, we found that several plant traits 354 correlating to die-off response and their resilience after disturbance were related 355 to their water acquisition strategies. Species with higher rates of defoliation (low 356 RAGC) exhibited lower SLA (which indicates a lower assimilation rate per unit 357 mass; Reich et al. 1997), higher $\delta^{13} \mathrm{C}$ (which is related with higher water use 358 efficiency and stomatic control; Farquhar et al. 1982; Domínguez et al. 2012), 359 and higher leaf water potential $(\Psi)$. These results suggest that some dominant 360 shrub species, such as $R$. officinalis and $C$. libanotis, in addition to stomatic 361 control, massively shed their leaves to cope the extreme conditions of water 362 deficit, probably as a mechanism for reducing the transpiring leaf surface and 363 thereby the rate of water loss (Pérez-Ramos et al. 2013). The existence of this 364 syndrome of semideciduous shrubs which drop their leaves and show very low 
365 values of leaf water potential under high water deficit has been previously 366 described in this community (Zunzunegui et al. 2005) and concurs with 367 observations in Mediterranean species (Saura-Mas and Lloret 2007) and desert 368 shrub communities (Smith et al.1995). The positive relationship between leaf 369 proline content and green cover (RAGC) would illustrate the stress associated 370 to the strategy of retaining green leaves, which in fact was negatively correlated 371 with leaf water potential (Zunzunegui et al. 2005). These species with high 372 defoliation and $\delta^{13} \mathrm{C}$ differs from those (L. stoechas, $T$. mastichina or $H$. 373 halimifolium) showing higher SLA and lower water use efficiency (WUE), which 374 were be able to maintain green biomass for a longer time period but were less 375 resilient at the medium term.

377 The role of root traits.- Our results also showed a relevant role of root traits in 378 species resistance to die-off. The sandy nature of the soil system facilitated the 379 interpretation of the root features due to an unusually homogeneous soil 380 environment. Accordingly, the most affected species by die-off (lower RGAC) in 381 our study site were those having higher RDMC. Thus, we found some 382 parallelism between root and above-ground traits for water-use; species with 383 both high values of SLA and low of RDMC would experience relative low 384 construction costs and would show a more exploitative resource-use strategy 385 (Villar and Merino 2001), presented a successful strategy to withstand extreme 386 climatic episodes. Also, species with higher resilience were those with wider 387 roots and lower root tissue density (TMDr), indicating a likely higher efficiency of 388 water uptake. Conversely, plants with high values of root tissue density are 389 commonly associated to a strategy characterized by a large investment in the 
390 structural features of roots and a limited capacity to acquire water in the upper

391 soil layer (Wahl and Ryser 2000).

393 The role of seed mass.- Resilience of species after the climatic event was also 394 positively related to their seed mass, likely because this trait determined the 395 success of seedling establishment and new recruits that achieved enough size 396 to account for community plant cover eight years after the climatic episode. 397 These successful recruits corresponded mainly to species with relatively large seeds (C. libanotis and $R$. officinalis, and to a lesser extent $H$. commutatum and $H$. halimifolium), which were able to remain abundantly in the soil bank and to 400 produce new cohorts of seedlings after the canopy opening resulting from die401 off (del Cacho and Lloret 2012). However, other species such as J. phoenicea, 402 with large-sized seeds and high rates of seedling survival, produced small seed 403 banks and few recruits, reliying its recovery on adult performance, at least at the 404 considered temporal scale (García et al. 2014). Conversely, species that 405 produced a large number of very small seeds ( $H$. picardii and $E$. scoparia) 406 showed a low resilience after die-off.

407 Overall, the observed relationship between seed mass and resilience 408 agrees with the role of seed mass for enhancing seedling survival (Moles and 409 Westoby 2006), particularly under drought stressful conditions (Westoby et al. 410 2002). This relationship supports the hypothesis of trade-off between stress 411 tolerance and fecundity proposing that in more stressful conditions, species with 412 large seeds tend to be favoured thanks to their advantage during the 413 establishment stage (Muller-Landau 2010). In the Doñana shrublands, the 414 increase of light and soil resources associated to the process of gap opening in 
415 the years after defoliation would produce a competition release that could 416 promote the successful recruitment of these particular species with larger 417 seeds, as supported by the positive effect of die-off on the number of seedlings.

418 Thus, species filling the soil bank with abundant, relatively large seeds would be 419 better suited to obtain advantage of this opportunity window, and thus 420 promoting community cover resilience.

422 Recruitment strategies after an extreme climatic event

423 Overall, the most affected plant species were those producing a higher number 424 of seedlings after the climatic episode, a feature observed in other 425 Mediterranean communities after natural disturbances such as fire (Lloret 426 1998). In fact, many of the species of this community exhibiting high recruitment 427 rates can be considered to show also a post-fire seeder strategy (Verdú and 428 Pausas 2007), indicating a possible convergence of responses following 429 different types of disturbances. The number of seedlings was negatively related 430 to seed size, as expected according to the classical trade-off between size and 431 number of seeds (Leishman 2001). However, seedlings from species producing 432 abundant, small seeds will eventually exhibit high mortality rates (Lloret et al. 433 1999), being other species with larger seeds such as $C$. libanotis and $R$. 434 officinalis the main contributors of the recovery of the community cover from 435 new recruits.

$436 \quad$ The species that showed a higher number of seedlings (after controlling 437 by the effect of canopy loss or die-off) were those having low-density, thinner 438 and $\mathrm{N}$-rich leaves, lower stomata control (i.e. less $\delta^{13} \mathrm{C}$ ).. This syndrome is 439 commonly associated with an acquisitive resource-use strategy. This is the 
440 case of the short-lived shrubs L. stoechas, T. mastichina and H. picardii. In spite

441 of their greater ability to establish as seedlings, these species showed a low 442 resilience and eventually they did not achieve dominance in the canopy, 443 probably as a result of their smaller size and their tendency to loss the canopy 444 cover even several years after the climatic event.

445 The significant relationship between recruitment and the main trend of 446 trait variation (first PCA axis) persisted for the juvenile stage. However, when 447 considering separately the different traits, it tended to disappear. Seedling 448 mortality in these Mediterranean environments is high during the first seasons 449 after emergence and it is subjected to a high stochasticity associated to 450 microhabitats (Lloret 1998). In fact, some species (such as $R$. officinalis and $C$. 451 libanotis) with intermediate scores in the first trait PCA axis were heavily 452 affected by die-off but reached to produce a large number of juveniles, which 453 will likely replace the damaged populations. This contrasts with species that 454 experienced similar cover losses but with less capacity to establish new 455 seedlings (E. scoparia and $U$. australis) or with high rates of seedling mortality 456 (H. commutatum). Other species (S. genistoides and J. phoenicea) were more 457 resistant thanks to moderate cover losses, in spite of producing few recruits. 458 The case of $H$. halimifolium seems different because they are relatively large 459 shrubs finding difficulties to restore the canopy after die-off while their quite 460 abundant number of seedlings experienced high mortality rates. These patterns 461 highlight the difficulties to scale-up broad species functional characterizations to 462 particular demographic processes. 
465 In spite of the contrasted patterns obtained in this study, we found that the 466 relationships between species functional traits and die-off responses were 467 limited to a relatively low number of functional attributes. There are several 468 reasons to interpret this limited ability of the species functional traits as 469 predictors of population-level processes. At the species level, within-species 470 variability of functional trait values may be equally important for interpreting 471 population responses to a particular environmental factor than species472 averaged values (Albert et al. 2011; Kichenin et al. 2013). Also, functional traits 473 often exhibit trade-offs between them due to functional, structural or 474 phylogenetic constraints (Reich et al. 2003; Cavender-Bares et al. 2009). Thus, 475 the effect of environmental drivers on a single attribute may be masked if traits 476 respond differently to co-occurring environmental factors. Finally, many 477 functional traits simultaneously obey to different environmental factors and they 478 may hardly show strong relationships with a single one - in our case, extreme 479 water deficit-. Overall, species may have similar traits but differ in others, 480 allowing diverse trait combinations that may promote species coexistence, for 481 instance under periods of low water availability (Pivovaroff et al. 2014). In fact, 482 correlations between plant functional traits and environmental factors have 483 been mainly found across wide abiotic or successional gradients or at regional 484 scale (Díaz et al 2004; Wright et al. 2004). Noticeably, the studied community 485 exhibited a quite homogeneous pattern of functional diversity when considered 486 in the context of the plant communities of the area (de la Riva et al. 2015). 487 
489 Our study provides a functional interpretation of the responses performed by 490 coexisting species to a climatic extreme episode causing vegetation die-off.

491 Current climatic tendencies of increasing climatic variability in some regions, 492 such as the Mediterranean basin, reinforce the relevance of studying the impact 493 of these climatic anomalies on community dynamics and ecosystem processes. 494 Although drought-induced die-off has caused great concern because of its large 495 impact on forests, it also affects other woody plant communities, such as 496 Mediterranean and semi-arid woodlands (Lloret and Granzow-de la Cerda 497 2013; Breshears et al. 2005), where it produces important changes on 498 ecosystem biodiversity and functioning (Royer et al. 2011). Similarly to other 499 drivers of global change, here we highlight the utility of using a trait-based 500 approach to assess ecosystem responses - changes in vegetation cover in this 501 case -. Nevertheless, the impact on ecosystem functioning would eventually 502 depend on the degree of coupling between traits sensitive to the environmental 503 change and traits with relevance on ecosystem functioning (Suding et al 2008).

504 Our study reveals the importance of selecting appropriate meaningful traits that 505 are as directly linked as possible with the specific environmental stressor. We 506 finally remark that functional traits can provide relevant insights to interpret post507 event resilience that can contribute to stabilize plant community after extreme 508 climatic events, particularly when combined with demographic attributes (Lloret 509 et al. 2012).

\section{Acknowledgements}

512 This study was supported by the projects CGL2009-08101, CGL2010-16373, 513 CGL2012-32965, DIVERBOS (CGL2011-30285-C02-01 and C02-02), AGAUR 
515 11/2013, and by European FEDER funds. Personnel from the ICTS-RBD kindly

516 supported the fieldwork. We thank the help of C. Padilla, C. Navarro and M.

517 Olmo during field sampling and trait measurements. Data of seed mass was

518 kindly provided by Jardín Botánico de Córdoba (Francisca Herrera). Isotopic

519 analysis was carried out in the LIE of EBD, CSIC, and N of leaves in the SCAI

520 of University of Córdoba.

521

522

523

524

525

526

527

528

529

530

531

532

533

534

535

536

537

538

539

540

541

542

543

544

545

546

\section{References}

Ackerly DD (2004) Functional strategies of chaparral shrubs in relation to seasonal water deficit and disturbance. Ecol Monogr 74:25-44

Aerts R (1995) The advantages of being evergreen. Trends Ecol Evol 10:402407

Albert CH, Grassein F, Schurr FM, et al. (2011) When and how should intraspecific variability be considered in trait-based plant ecology? Pers Plant Ecol Evol Syst 13: 217-235

Allen CD, Macalady AK, Chenchouni H, Bachelet D, McDowelll, N, Vennetier M, Kitzberger T, Rigling A, Breshears D, Hogg EH, Gonzalez P, Fensham R, Zhang Z, Castro J, Demidova N, Limm JH, Allard G, Running SW, Semerci A, Cobb N (2010) A global overview of drought and heatinduced tree mortality reveals emerging climate change risks for forests. For Ecol Manage 259:660-684

Breshears DD, Cobb, NS, Rich PM et al. (2005) Regional vegetation die-off in response to global-change-type drought. Proc Nat Acad Sci USA 102: 15144-15148

Cavender-Bares J, Cortes P, Rambal S, Joffre R, Miles B, Rocheteau A (2005) Summer and winter sensitivity of leaves and xylem to minimum freezing temperatures: a comparison of cooccurring Mediterranean oaks that differ in leaf lifespan. New Phytol 168: 597-612 
547 Cavender-Bares J, Kozak KH, Fine PVA, Kembel SW (2009) The merging of community ecology and phylogenetic biology. Ecol Let 12: 693-715

549 Chapin FS III (2003) Effects of plant traits on ecosystem and regional processes: a conceptual framework for predicting the consequences of global change. Ann Bot 91:455-463

Diaz S, Cabido M, Casanoves F (1998) Plant functional traits and environmental filters at a regional scale. J. Veg Sci 9:113-122

Diaz S, Hodgson JG, Thompson K (2014) The plant traits that drive ecosystems: evidence from three continents. J Veg Sci 15: 295-304

Díaz-Delgado R (2006) Evento de mortalidad en la vegetación terrestre del Parque Nacional de Doñana. Estación Biológica de Doñana, CSIC, Sevilla

Domínguez MT, Aponte C, Pérez-Ramos IM, García LV, Villar R, Marañón T (2012) Relationships between leaf morphological traits, nutrient concentrations and isotopic signatures for Mediterranean woody plant species and communities. Plant Soil 357:407-424

Easterling D, Meehl GA, Parmesan C, Changnon SA, Karl TR, Mearns LO, (2000) Climate extremes: Observations, modelling, and impacts. Science 289: 2068-2074

Esther A, Groeneveld J, Enright NJ, Miller BP, Lamont BB, Perry GLW, Blank $F B$, Jeltsch $F(2010)$ Sensitivity of plant functional types to climate change: classification tree analysis of a simulation model. J Veg Sci 21: 447-461

Farquhar GD, Learyb MHO, Berry JA (1982) On the relationship between Carbon isotope discrimination and the intercellular Carbon Dioxide concentration in leaves. Aust J Plant Physiol 9:121-137

578 Granda E, Scoffoni C, Rubio-Casal AE, Sack L, Valladares F (2014) Leaf and 579 stem physiological responses to summer and winter extremes of woody $580 \quad$ species across temperate ecosystems. Oikos 123:1281-1290 
581 García C, Moracho E, Díaz-Delgado R, Jordano P (2014) Long-term expansion of juniper populations in managed landscapes: patterns in space and time. J Ecol 102:1562-1571

$584 \quad$ IPCC (2013) Climate change 2013: The physical scientific basis. WMO, UNEP

585 Karavatas S, Manetas Y (1999) Seasonal patterns of photosystem II 586 photochemical efficiency in evergreen sclerophylls and drought semi587 588 deciduous shrubs under Mediterranean field conditions. Photosynthetica 36:41-49

590

591

Kichenin E, Wardle DA, Peltzer DA, Morse CW, Freschet GT (2013) Contrasting effects of plant inter- and intraspecific variation on community- level trait measures along and environmental gradient. Funct Ecol 27:1254-1261

Koepke DF, Kolb TE, Adams HD (2010) Variation in woody plant mortality and dieback from severe drought among soils, plant groups, and species within a northern Arizona ecotone. Oecologia 163:1079-1090

Larcher W (1981) Low temperature effects on Mediterranean sclerophylls: an unconventional viewpoint. In: Margaris NS, Mooney HA (eds) Components of productivity of Mediterranean-climate regions - basic and applied aspects. Dr W. Junk Publishers, The Hague, pp 259-266

Leishman MR (2001) Does the seed size/number trade-off model determine plant community structure? An assessment of the model mechanisms and their generality. Oikos 93: 294-302

Lloret F (1998) Fire, canopy cover and seedling dynamics in Mediterranean shrubland of northeastern Spain. J Veg Sci 9:417-430

Lloret F, Casanovas C, Peñuelas J (1999) Seedling survival of Mediterranean shrubland species in relation to root:shoot ratio, seed size and water and nitrogen use. Funct Ecol 13:210-216

Lloret F, Keeling E, Sala A (2011) Components of tree resilience: effects of successive low-growth episodes in old ponderosa pine forests. Oikos 120:1909-1920

Lloret F, Escudero A, Iriondo JM, Martínez-Vilalta J, Valladares F (2012) Extreme climatic events and vegetation: the role of stabilizing processes. Glob Change Biol 18: 797-805 
614 Lloret F, Martínez-Vilalta J, Serra-Díaz J, Ninyerola M (2013) Relationship between projected changes in climatic suitability and demographic and functional traits of forest tree species in Spain. Clim Change 120: 449462

644 Oliveira G, Peñuelas J (2004) Effects of winter cold stress on photosynthesis

Lloret F, Granzow-de la Cerda I (2013) Plant competition and facilitation after extreme drought episodes in Mediterranean shrubland: does damage to vegetation cover trigger replacement by juniper woodland? J. Veg Sci 24 : 1020-1032

Logullo MA, Salleo S (1993) Different vulnerabilities of Quercus ilex L. to freeze - and summer drought - induced xylem embolism: an ecological interpretation. Plant Cell Environ 16:511-519

Martínez F, Merino O, Martín A, García Martín D, Merino J (1998) Belowground structure and production in a Mediterranean sand dune shrub community Plant Soil 201:209-216

Martínez-Vilalta J, Mencuccini M, Vayreda J, Retana J (2010) Interspecific variation in functional traits, not climatic differences among species ranges, determines demographic rates across 44 temperate and Mediterranean tree species. J Ecol 98:1462-1475

Martínez-Vilalta J, Breshears DD, Lloret F (2012) Drought-induced forest decline: causes, scope and implications. Biol Let 8:689-691

McCormack ML, Adams TS, Smithwick, EAH, Eissenstat, DM (2012) Predicting fine root lifespan from plant functional traits in temperate trees. New Phytol 195:823-831

Mitrakos K (1980) A theory for Mediterranean plant life. Acta Oecol / Oecol Plant 1:245-252

Moles AT, Westoby M (2006) Seed size and plant strategy across the whole life cycle. Oikos 113:91-105

Muller-Landau HC (2010) The tolerance-fecundity trade-off and the maintenance of diversity in seed size. Proc Nat Acad Sci USA 107:42424247 and photochemical efficiency of PSII of the Mediterranean Cistus albidus L. and Quercus ilex L. Plant Ecol 175:179-191 
647 Pérez-Harguindeguy N, Díaz S, Garnier E, Lavorel S, Poorter H, Jaureguiberry

648

649

650

651

652

653

654

655

656

657

658

659

660

661

662

663

664

665

666

667

668

669

670

671

672

673

674

675

676

677

678

679

680 P, Bret-Harte MS, Cornwell WK, Craine JM, Gurvich DE, Urcelay C, Veneklaas EJ, Reich PB, Poorter L, Wright IJ, Ray P, Enrico L, Pausas JL, de Vos AC, Buchmann N, Funes G, Quétier F, Hodgson JG, Thompson K, Morgan HD, ter Steege H, van der Heijden MGA, Sack L, Bonder B, Poschlod P, Vaieretti MV, Conti G, Staver AC, Aquino S, Cornelissen JHC (2013) New handbook for standardised measurement of plant functional traits worldwide. Aust J Bot:167-234

Pérez-Ramos IM, Roumet C, Cruz P, Blanchard A, Autran P, Garnier E (2012) Evidence for a "plant community economics spectrum" driven by nutrient and water limitations in a Mediterranean rangeland of southern France. $J$ Ecol 100:1315-1327

Pérez-Ramos IM, Volaire F, Fattet M, Blanchard A, Roumet C (2013) Tradeoffs between functional strategies for resource-use and drought-survival in Mediterranean rangeland species. Environ Exp Bot 87:126-136

Pivovaroff AL, Sack L, Santiago LS (2014) Coordination of stem and leaf hydraulic conductance in southern California shrubs: a test of the hydraulic segmentation hypothesis. New Phytol 302:842-850

Poorter H, Niinemets Ü, Poorter L, Wright IJ, Villar R (2009) Causes and consequences of variation in leaf mass per area (LMA): a meta-analysis. New Phytol 182:565-588

Prieto I, Roumet C, Cardinael R, Dupraz C, Jourdan C, Kim JH, Maeght JL, Mao Z, Pierret A,Portillo N, Roupsard O, Thammahacksa C, Stokes A (2015) Root functional parameters along a land-use gradient: evidence of a community-level economics spectrum. J Ecol 103:361-373

Reich PB, Walters MB, Ellsworth DS, Vose JM, Volin JC, Gresham C, Bowman WD (1998) Relationships of leaf dark respiration to leaf nitrogen, specific leaf area and leaf life-span: a test across biomes and functional groups. Oecologia 114:471-482

Reich PB, Wright IJ, Cavender-Bares J, Craine JM, Oleksyn J, Westoby M, Walters MB (2003) The evolution of plant functional variation: traits, spectra and strategy. Int J Plant Sci 164 S3: S143-S164

Reyer CPO, Leuzinger S, Rammig A, Wolf A, Bartholomeus RP, Bonfante A, De Lorenzi F, Dury M, Glonig P, Jaoudé RA, Klein T, Kuster TM, Martins 
681

682

683

684

685

686

687

688

689

690

691

692

693

694

695

696

697

698

699

700

701

702

703

704

705

706

707

708

709

710

711

712

713

M, Niedrist G, Riccardi M, Wohlfahrt G, De Angelis P, de Dato G, François L, Menzel A, Pereira M (2013) A plant's perspective of extremes: Terrestrial plant responses to changing climatic variability. Glob. Change Biol. 19: 75-89

Royer PD, Cobb NS, Clifford MJ, Huang, CY, Breshears DD, Adams HD, Villegas JC (2011) Extreme climatic event-triggered overstorey vegetation loss increases understorey solar input regionally: primary and secondary ecological implications. J Ecol 99:714-723

Ruíz-Robleto J, Villar R (2005) Relative growth rate and biomass allocation in ten woody species with different leaf longevity using phyllogenetic independent contrasts (PICs). Plant Biol 7:484-494

Saura-Mas S, Lloret F (2007) Leaf and shoot water content and leaf dry matter content of Mediterranean woody species with different post-fire regenerative strategies. An Bot 99:545-554

Saura-Mas S, Lloret F (2014) Adult root structure of Mediterran shrubs: relationship with post-fire regenerative syndrome. Plant Biol 16:147-154

Shih-Chieh K, Ganguly Auroop R (2011) Intensity, duration, and frequency of precipitation extremes under 21st-century warming scenarios. J Geo Res-Atmosph 112:D16119

Smith SD, Herr CA, Leary KL, Piorkowski JM (1995) Soil-plant water relations in a Mojave Desert mixed shrub community: a comparison of three geomorphic surface. J Arid Environ 29:339-351

Suding KN, Lavorel S, Chapin FS, Cornelissen JHS, Diaz S, Garnier E, Goldberg D, Hooper D, Jackson S, Navas ML (2008) Scaling environmental change through the community-level: a trait-based response and- effect framework for plants. Glob Change Biol 14:11251140

Thuillier W, Lavorel S, Sykes MT, Araujo MB (2006) Using niche-based modelling to assess the impact of climate change on tree functional diversity in Europe. Div Dist 12:49-60

Verdú M, Pausas JG (2007) Fire drives phylogenetic clustering in Mediterranean Basin woody plants communities. J Ecol 95:1316-1323

Villar R, Ruiz-Robleto J, de Yong Y, Poorter H (2006) Differences in construction costs and chemical composition between deciduous and 
evergreen woody species are small as compared to differences among families. Plant Cell Environ 29:1629-1643

717 Villar R, Merino JA (2001) Comparison of leaf construction costs in woody species with differing leaf life-spans in contrasting ecosystems. New Phytol 151:213-226

720

Wahl S, Ryser P (2000) Root tissue structure is linked to ecological strategies of grasses. New Phytol 148:459-471

722 Westoby M, Falster DS, Moles AT, Vesk PA, Wright IJ (2002) Plant ecological strategies: some leading dimensions of variation between species. Ann Rev Ecol Syst 33:125-159

Willson CJ Jackson RB (2006) Xylem cavitation caused by drought and freezing stress in four co-occurring Juniperus species. Physiol Plant 127:374-382

727 Wright IJ, Westoby M (2002) Leaves at low versus high rainfall: coordination of structure, lifespan and physiology. New Phytol 155:403-416

Wright IJ, Reich PB, Westoby M, Ackerly DD, Baruch Z, Bongers F, CavenderBares J, Chapin T, Cornelissen JHC, Diemer M, Flexas J, Garnier E, Groom PK, Gulias J, Hikosaka K, Lamont BB, Lee T, Lee W, Lusk C, Midgley JJ, Navas ML, Niinemets U, Oleksyn J, Osada N, Poorter H, Poot P, Prior L, Pyankov VI, Roumet C, Thomas SC, Tjoelker MG, Veneklaas EJ, Villar R (2004) The worldwide leaf economics spectrum. Nature 428:821-827

Zunzunegui M, Barradas MD, Ain-Lhout F, Clavijo A, Novo FG (2005). To live or 739 


\section{$740 \quad$ Figure Legends}

742 Figure 1. Mean annual temperature and total precipitation in Doñana NP. Right,

743 upper corner: box indicating medians, 25 and $75 \%$ percentiles and extreme

744 values for the period 1978-2013. Data correspond to hydrological years (from

745 September until August). Arrows indicate the die-off year (2004-05).

747 Figure 2. Species plant cover (\%) estimated from transects contacts 748 intercepting plants of the plots sampled in 2007 and 2013. Values prior to the 749 event correspond to the sum of living and dead plants parts in 2007. Data 750 correspond to the pooled values of the eighteen surveyed plots.

751

752 Figure 3. Principal Component Analysis (PCA) biplot of functional traits 753 (abbreviations as in Table 1) and species (abbreviations, CL: Cistus libanotis, 754 HC: Halimium commutatum, HH: Halimium halimifolium, HP: Helicrysum 755 picardii, LS: Lavandula stoechas, RO: Rosmarinus officinalis, SG: 756 Stauracanthus genistoides, TM: Thymus mastichina, UA: Ulex australis, ES: 757 Erica scoparia, JP: Juniperus phoenicea).

759 Figure 4. Relationship between Remaining Aerial Green Cover (RAGC) 760 measured in 2007 and (a) Specific leaf area (SLA), (b) $\delta 13 C$ (\%o), (c) Leaf water 761 potential $(\mathrm{Y})$ and (d) Root dry matter content (RDMC) of coexisting species in 762 Doñana NP shrubland affected by climatic-induced die-off in 2005. RDMC was 763 fitted to RAGC after excluding the outlier Rosmarinus officinalis (within a 764 square, see Results section).

Figure 5. Relationship between Relative Resilience (RR) measured in 2013 and (a) $\delta 13 \mathrm{C} \mathrm{( \% o),} \mathrm{(b)} \mathrm{Seed} \mathrm{mass} \mathrm{(Smass),} \mathrm{(c)} \mathrm{Root} \mathrm{diameter} \mathrm{(Rdiam)} \mathrm{and} \mathrm{(d)}$ Tissue mass root density (TMDr) of coexisting species in Doñana NP shrubland affected by climatic-induced die-off in 2005. 

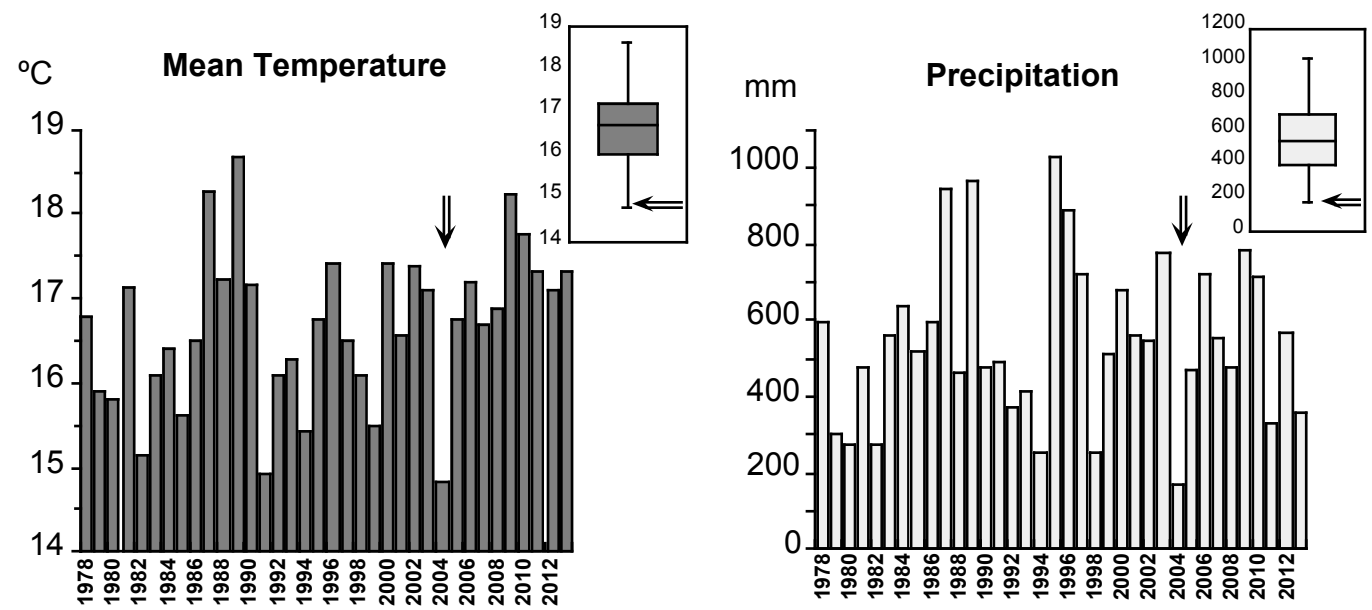

Figure 1

781

782 


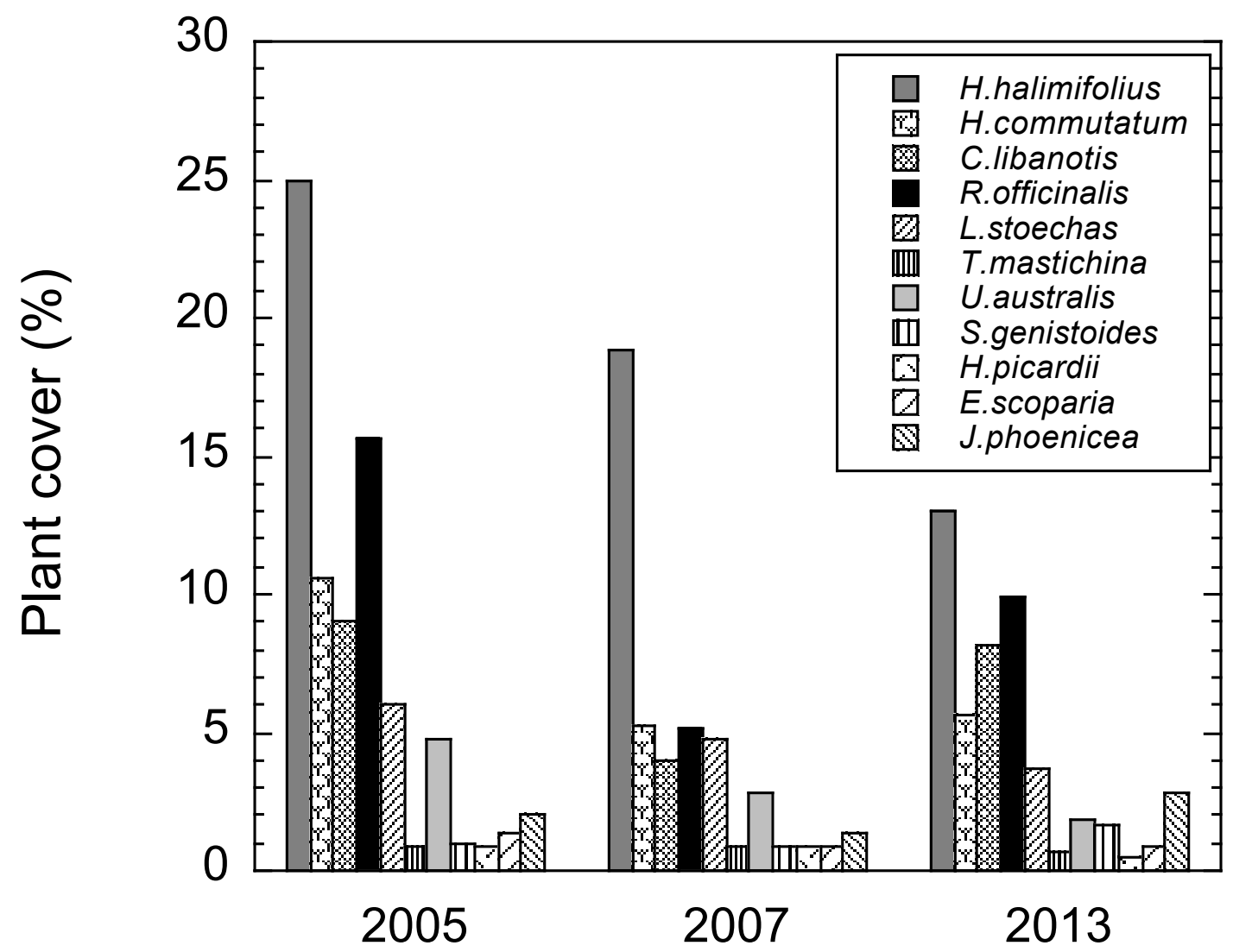

784

785

Figure 2

786

787 


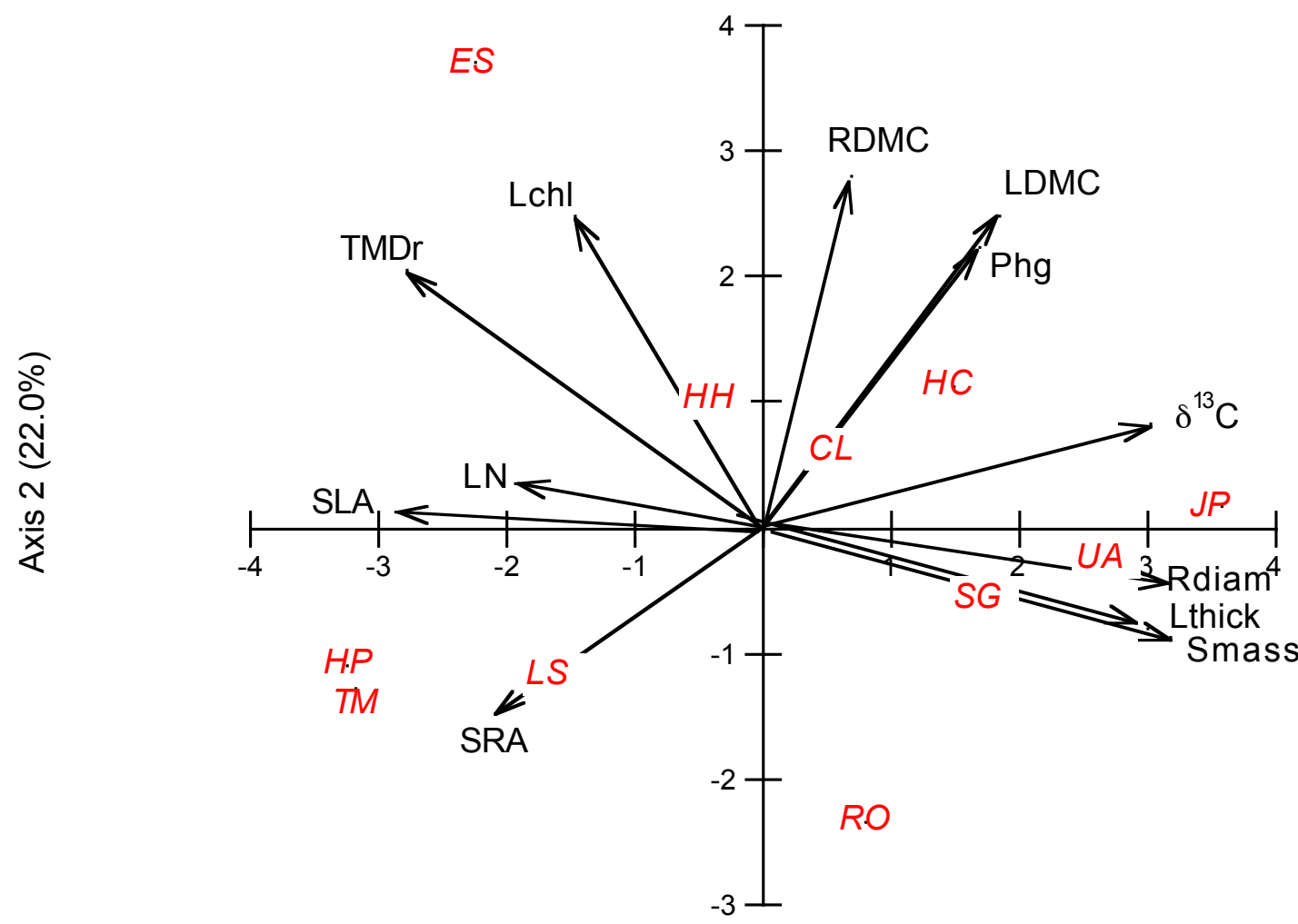

Figure 3.

792

793 

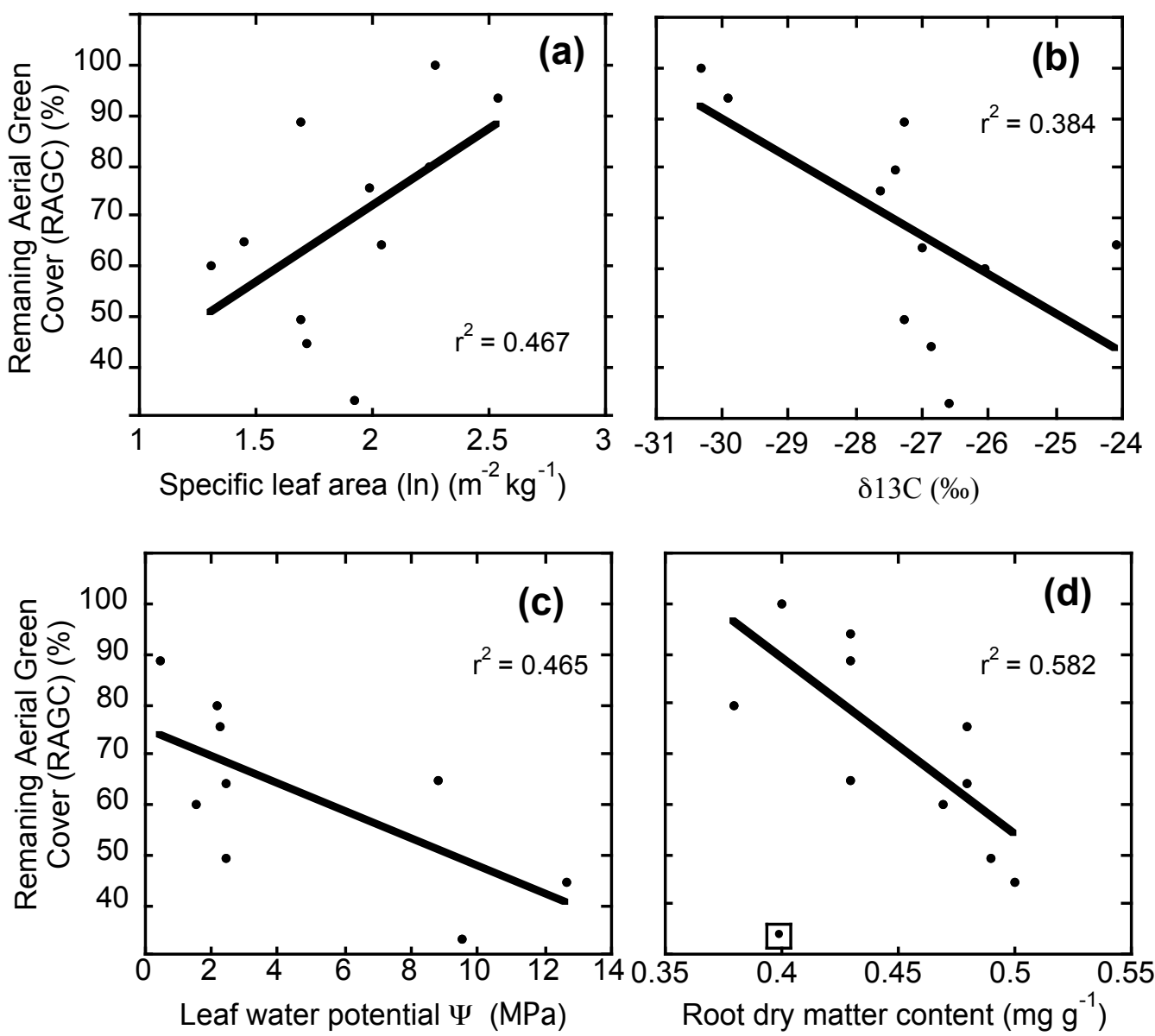

795

796

797

Figure 4

798 

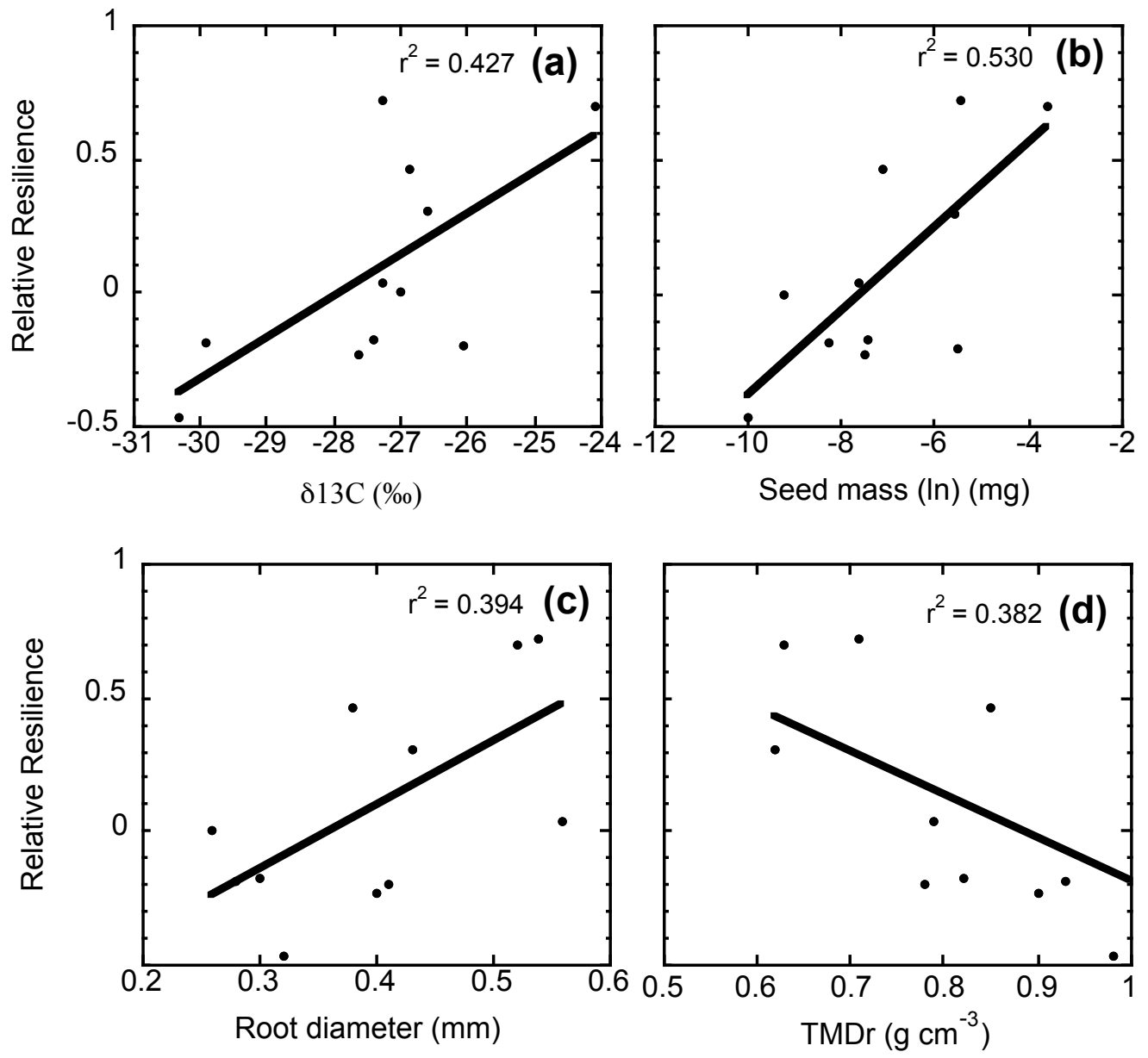

799

800

801

802

Figure 5

803

804

805 
Table 1. List of the functional traits considered in this study, their abbreviations, units and their main role in plant functioning.

808

809

\begin{tabular}{lccl}
\hline \multicolumn{1}{c}{ Trait } & Abbreviation & Unit & \multicolumn{1}{c}{ Functional role } \\
\hline Specific leaf area & SLA & $\mathrm{m}^{2} \mathrm{~kg}^{-1}$ & Light and carbon acquisition and water use \\
Leaf dry matter content & LDMC & $\mathrm{mg} \mathrm{g}^{-1}$ & Carbon acquisition and water use \\
Leaf thickness & Lthick & $\mathrm{mm}$ & Light and carbon acquisition \\
Leaf nitrogen concentration & $\mathrm{LN}$ & $\%$ & Nutrient acquisition and use \\
Leaf chlorophyll & LChl & $\mathrm{\mu g} \mathrm{g}^{-1}$ & Light and carbon acquisition \\
Leaf proline content & Prol & $\mathrm{\mu g} \mathrm{g}^{-1}$ & Drought stress \\
Isotopic carbon fraction & $\delta^{13} \mathrm{C}$ & $\% \circ$ & Carbon acquisition and water use efficiency \\
Leaf water potential & $\Psi$ & $\mathrm{MPa}^{-}$ & Water acquisition and use \\
Specific root area & SRA & $\mathrm{m}^{2} \mathrm{~kg}^{-1}$ & Water and nutrient acquisition \\
Root diameter & Rdiam & $\mathrm{mm}^{-1}$ & Water and nutrient acquisition \\
Tissue mass root density & TMDr & $\mathrm{g} \mathrm{cm}^{-1}$ & Water and nutrient acquisition \\
Root dry matter content & RDMC & $\mathrm{mg} \mathrm{g}^{-1}$ & Water and nutrient acquisition \\
Plant height & Phg & $\mathrm{m}$ & Light and carbon acquisition \\
Seed mass & Smass & $\mathrm{mg}^{2}$ & Recruitment \\
\hline
\end{tabular}

810

811 
812 Table 2. Results of GLMs describing the number of seedlings (log-transformed) 813 recorded in 2007, two years after the die-off episode, in relation to different 814 plant traits. Models included species defoliation, estimated from contacts 815 transects (see Methods). Species die-off was not significant in the LN model 816 and it was removed. Only traits exhibiting a significant relationship are shown.

817

\begin{tabular}{|c|c|c|c|c|c|c|c|}
\hline & \multicolumn{3}{|c|}{ Trait } & \multicolumn{3}{|c|}{ Defoliation } & \multirow{2}{*}{$\begin{array}{c}\text { Whole } \\
\text { model } \\
r^{2}\end{array}$} \\
\hline & estimate & $\mathrm{F}$ & $p$ & estimate & $F$ & $p$ & \\
\hline SLA & 5.60 & 6.03 & 0.049 & 1.12 & 10.67 & 0.017 & 0.638 \\
\hline LDMC & -28.63 & 10.43 & 0.018 & 0.50 & 6.53 & 0.043 & 0.735 \\
\hline Lthick & -2.74 & 19.93 & 0.004 & 0.62 & 15.18 & 0.08 & 0.832 \\
\hline$\delta^{13} \mathrm{C}$ & -0.82 & 11.16 & 0.016 & 0.74 & 12.87 & 0.012 & 0.746 \\
\hline LN & 5.35 & 6.29 & 0.036 & - & - & - & 0.440 \\
\hline Smass & -0.86 & 21.32 & 0.004 & 0.46 & 9.09 & 0.024 & 0.841 \\
\hline First PCA axis & -0.66 & 35.38 & 0.001 & 0.69 & 29.29 & 0.002 & 0.895 \\
\hline
\end{tabular}

818

819

820 

Supplementary Material
Click here to download St Supplementary Material
Click here to download Supplementary Material: Electronic Supplemental Material.pdf

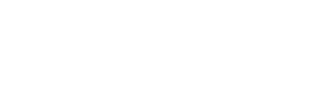

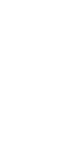

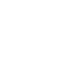

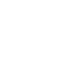
(1)

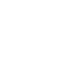

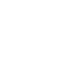

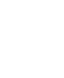

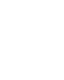

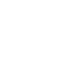
西 